\title{
Determinant Factors of Consumers' Green Purchase Intention: The Moderating Role of Environmental Advertising
}

\author{
Brahim Chekima ${ }^{1}$, Syed Azizi Wafa Syed Khalid Wafa ${ }^{1}$, Oswald @ Aisat Igau ${ }^{1} \&$ Sohaib Chekima $^{2}$ \\ ${ }^{1}$ Faculty of Business, Economics \& Accountancy, Universiti Malaysia Sabah, Malaysia \\ ${ }^{2}$ Department of Languages, Literatures \& Cultures, University at Albany, New York, United States of America \\ Correspondence: Brahim Chekima, Faculty of Business, Economics and Accountancy, Universiti Malaysia \\ Sabah, Jalan UMS, 88400, Kota Kinabalu, Sabah, Malaysia. Tel: 60-12-844-4253. E-mail: \\ brahim_hks@yahoo.com
}

Received: December 20, 2014 Accepted: January 13, 2015 Online Published: April 20, 2015

doi:10.5539/ass.v11n10p318 URL: http://dx.doi.org/10.5539/ass.v11n10p318

\begin{abstract}
This paper aims to determine the environmental attitude, product functional aspects as well as cultural values that influence the green purchasing intention and lastly address the role of environmental advertising as a moderator. Inadequate information related to green purchase intention in Malaysia has become a main barrier to local and international marketers to understand consumer behavior to develop a comprehensive distribution and marketing strategies of green products in the country where the trend is still new. A total of 337 self-administered questionnaires were obtained from consumers through convenience sampling. The results indicated that environmental attitude, eco-label and cultural value (long-term orientations) are significant influencers of green purchase intention. Further investigation revealed that environmental advertising enjoys a positive and significant moderating effect on the relationship between the independent variables and green purchase intention. The results provide insights for marketers with respect to the factors influencing consumers green products purchase intention. Also, this paper highlights the importance of culture, environmental advertising, and their linkage towards green purchase intention. This will aid marketers to develop holistic strategies and tactics in accordance with the finding to appeal to consumers, which ultimately achieve the anticipated sales of green products requiring different marketing strategy than conventional products. Implication for marketers is further discussed.
\end{abstract}

Keywords: green purchase intention, theory of planned behavior, environmental attitude, eco-label, long-term orientation, environmental advertising

\section{Introduction}

The rapid development of economy and advancement of technology can no longer be separated from the negative effects on the environment. This has in turn contributed to the major environmental deterioration and catastrophe that we are facing nowadays. Recently, environmental problems have resurfaced as a top issue to the media and green marketing research field. Statistics shows that 30-40 percent of this deterioration is contributed by the unhealthy consumers' consumption pattern. Climate change, ozone layer depletion, air and water pollution, deforestation, hazardous waste, acid rain as well as loss of flora and fauna species are some of the examples of human carelessness. Hence, a change towards more environmental friendly consumption patterns is vital.

Despite this fact, studies across the globe show contradiction in consumers' green claims and their actions through their consumption at this time. There is skepticism about how committed consumers are to buying green products. Bonini and Oppenheim (2008) stated "consumers say they want to buy environmentally friendly product and to reduce their impact on the environment, but when they get to the supermarket or cash register; their Earth-minded sentiments die on the vine". In addition, Wong et al., (1996) and Aspinall (1993) highlighted that despite evidence proposed that society is increasingly concerned about the environment, yet many green products have yet to achieve the anticipated degree of market success.

In the course of unraveling the problem of green purchase intention amongst Malaysians, this research is motivated by Chen and Chai (2010) who claimed it's due to the absence of adequate information on green purchase intention and green behavior of Malaysian consumers, making it difficult for existing and potential 
green product producers and marketers to enter and retain a position in the Malaysia's market. Thus, the researchers identified and investigated the most relevant variables which are environmental attitude (EA), eco-label (EL), and long-term orientation (LTO) on green purchase intention (GPI). The choice of the independent and moderating variables were driven based on the inconsistent result differ from one country to another, lack of research and some were discussed in other field of study but not the green purchase intention. Also this research is among the earliest that incorporated cultural value such as long-term orientation (LTO) into investigation. Hence this will provide a deeper understanding of green purchase intention by focusing on how long-term orientation drive/influence green consumptions as well as their linkage to each other. In addition, environmental advertising (A) included in the framework by examining their moderating effect between IV's and DV.

\section{Literature Review}

\subsection{Green Purchase Intention}

Consumer's purchase intention is well-known as a subjective and broad field in consumer behavior and part of purchase decision making. People across the globe tend to prove the different response towards many determinants that believed to stimulate one's purchase intention. Marketers, researches and academician are increasingly running tests and research to identify the best determinant or approach that can create intention of a particular product to their targeted customers and customize it to them in which latter might engage them in a real purchase. Scholars by navigating the purchasing process, found one of the pillars that make the whole purchasing process to be the purchase intention. In general, Spears and Singh (2004) along with Peter and Olson (2008) agreed that purchase intention (PI) can be defined as a consciously decided plan to make an effort to purchase a particular product or service.

Aligned with the definitions above, Lee (2008) defined green purchasing as "the purchasing of procurement efforts which give preferences to products or services which are least harmful to the environmental and human health". In addition, Nik Abdul Rashid (2009) conceptualized green purchase intention as the probability and willingness of an individual to give preference to green products over conventional products in their purchase considerations. While Chan (2001), defined green purchasing as a specific kind of eco-friendly behavior that consumers perform to express their concern to environment.

Bergeron (2004) quoted that, "research in social psychology suggests that intentions are the best predictor of an individual's behavior because they allow each individual to independently incorporate all relevant factors that may influence the actual behavior". This is supported by Armstrong et al., (2000) work which found out that purchase intention is an accurate measure of future sales compared to other sales forecasting tools in general. Besides, it also provides a more precise forecast rather than just an approximate of past sales trends. Adding to this, Newberry et al., (2003) stated that purchase intention is common tools used in predicting purchase behavior. Correspondingly, the most comprehensive theory to assist in explaining the effect of variables on purchase intention is the Theory of Planned Behavior (TPB) (Ajzen, 1985; 1991).

\subsection{Environmental Attitude and Green Purchase Intention}

A person's attitude varies from one and another and can be positive or negative and sometimes can simultaneously possess both positive and negative attitudes toward the item in question of a place, thing, event or person. Consistent with attitude statements' above, Nik Abdul Rashid (2010) defined environmental attitude in a more specific context as "a learned predisposition to respond consistency favorable or unfavorable manner with respect to the environment". Correspondingly, Schultz and Zelenzy (2000) denote those environmental attitudes are rooted in a person's concept of self and the degree to which an individual perceives himself or herself to be an integral part of the natural environment. There has been consistent empirical proof associating a positive stimulus between environmental attitude and behavior (Rashid, 2009; Chen \& Chai 2010; Mun, 2009, Laroche et al., 2001). These studies have also point out that a person will show great emotional attachment to environmental wellbeing or more likely to form a more positive environmental action despite having little concern on the environment. Laroche et al., (2001) affirm that attitude as opposed to concern and knowledge, found to be highly significant determinants of an individual willingness to pay premium price in exchange for green products and make a shift towards sustainable consumption. The works by (Chen \& Chai, 2010; Stern \& Dietz, 1994; Vining \& Ebreo, 1992; Hopper \& Nielson, 1991) explained that attitude of the consumer towards environmental protection regarded as a personal norm where it refers to the feeling of moral obligation of consumers. It is also a powerful motivator of environmental behavior (Stern \& Dietz, 1994; Vining \& Ebreo, 1992; Hopper \& Nielson, 1991). For instance, this condition is also well considered as the extent to which people feel obliged towards environmental harmony and preservation as well suggested that this attitude characterized as a morally 
demanding. The more a person is morally obliged to protect the environment and save the limited natural source on earth, the more positive attitude will be expressed in behaviors or actions. In other words, the more positive environmental attitude will lead to a stronger intention to perform an environmental behavior and vice versa.

\subsection{Eco-Label and Green Purchase Intention}

Eco label has been a very importantly tackled topic by scholars in the marketing field as a tool in influencing consumers purchase intention for green products in which attached to this product packaging. A report by the Massachusetts Department of Environmental Protection (2002) suggested that the difficulty in identifying and locating green products is one of the barriers for purchasing green products. Giridhar (1998) referred to eco-labels as the product's collective environmental performance. D'Souza et al., (2006) reported that eco-labels are increasingly being used by firms to promote the identification of their green products. Eco-labels are potentially attractive instruments informing consumers about the environmental impact of their purchasing decisions, while simultaneously providing producers with a tool for extracting market place preference and thus market share (Rashid, 2009). In the same study by Nik Abdul Rashid (2009), awareness of eco-label has been found to yield a positive effect on consumer's green product purchase intention. Therefore it is established from several previous studies that eco-labels have influence on green product preferences especially those with strong concern for the environmental.

\subsection{Long-term Orientation and Green Purchase Intention}

Long-term orientation is among the dimensions of cultural orientation that deals with time-past, present and future. Long-term orientation is a prominent facet of national culture values and of itself influences consumers' decision-making process (Bearden et al., 2006). Hofstede (2001) referred LTO "as a tendency towards the future, which stands for fostering of virtues oriented towards future reward, in particular, perseverance and thrift". In other way, it relates to how much society values long-standing compared to short term values and tradition. To the authors' best knowledge, this is among the earliest research that attempt to incorporate and investigate the influence of long-term orientation on green purchase intention field. A study by Sian et al. (2010), compared between the Malays and Chinese on the subject of culture and consumer behavior, found out that the Malays has scored a higher score of long-term orientation than the Chinese respondents and affirms that Malays also concern about the future and their consequences of actions regarding their present and future purchasing behavior. Bearden et al., (2006) suggested that long-term orientation influences ethical values level of a person that referred as the extent to which individuals considered accepted norms of right and wrong in their decisions. Thus, it would be expected that those who plan for future success would be less likely to engage in unethical behavior (conventional purchasing behavior) because such behavior if discovered holds very negative long-term consequences as this will have impact on environment deterioration. Hence, long-term oriented person will more likely to plan ahead before making purchase and are less tempted by immediate desires or quick outcome derive from their purchase.

\subsection{Environmental Advertising and Green Purchase Intention}

Previous studies on this subject, declared that green advertisement has shown a promising effect and enhanced consumers' attitude towards green purchasing intention. Haykto and Matulich (2008) identified several ways of consumers' response in expressing the green advertising effectiveness, in terms of willingness to pay premium price, trust the product safety and believed less harm as well as through loyalty. For instance, Chase and Smith (1992) reported that 70 percent of the respondent in their survey claimed to be influenced by labeling on the products and environmental messages. Additionally, a study based in Malaysia by Tsen et al., (2005) suggested that future research may include variable such as environmental advertisement programs in the research which could influence consumers intention and purchasing behavior to pay extra for green products. Applying the Theory of Planned Behaviour (TPB), Litvine and Wüstenhagen (2011) investigated consumers' attitude towards green power and demonstrated that increasing messages allowed consumers to recognize the advantage of purchasing green power and it would significantly enhance green power market.

However, in the same study by Chase and Smith (1992), the researchers found that more than half of the respondents stated that they pay less attention to environmental messages due to excess usage of exaggeration and lurid language. Moreover, Chase and Smith (1992) reported that majority of the sample agreed that environmental advertising is somehow not trustworthy in sense of communicating the information and benefits of green products. Rahbar and Abdul Wahid (2011) also found similar finding where respondents in terms of Penang's consumer in which environmental advertisement is not significant on purchasing behavior however it serves as a platform or source to enhance their knowledge related to green products.

In addition, Bator and Cialdini (2000) suggested that message involvement is critical factor in broad behaviors 
and proper indication of messages is one of the main strategies to enhance environmental behavior through information share. Thus, it is assumed that when a person has a favorable attitude towards green advertising, he or she will ultimately express a higher intention to buy green products and vice versa. Ali et al., (2011) and Haykto and Matulich (2008), believed that environmental advertising to have indirect influence on consumers' attitude towards green purchase behavior. Thus, study in hand employed environmental advertising as a moderator to confirm its effect and shed light on its important aspects to aid green product retailers to design and execute environmental advertisement.

\section{Methodology}

\subsection{Proposed Model and Hypotheses}

By reviewing the related literature, this part sets out the research model of this study in Fig. 1 to present the developed relationship between all the variables under investigation. In brief, the model postulates that a person's environmental attitude, perception on eco-label and exposure to environmental advertising relating to environmental issues will significantly influence green products purchase intention to. This postulation is based upon relevant literature discussed above and also the general belief that a person's are the major factors of his intention to act. Thus, TPB is relevant in this research with the following assumptions that consumer have a complete volitional control on purchase intention, consumers use the available information in a systematic and rational manner as well reflect the implications of their actions before they decide to involve or not to in an identified behaviors (Fishbein \& Ajzen, 1975).

Lastly, to capture the possible cultural influence of long-term orientation (LTO) on green purchase intention, a relevant factor was incorporated into the proposed model. In view of previous discussion and general notion that cultural values is an inherent underlying beliefs and important force shaping individuals view about something or an issue that a specific behavior is desirable or not involves giving value to the environment or not (McCarty \& Shrum, 1994). LTO has thus been hypothesized as excreting a direct positive effect on consumer's green purchase intention. For reference, all the direct relationship and indirect relationship (moderator) hypothesized pertinent to the proposed model been formulated accordingly and presented in the figure below:

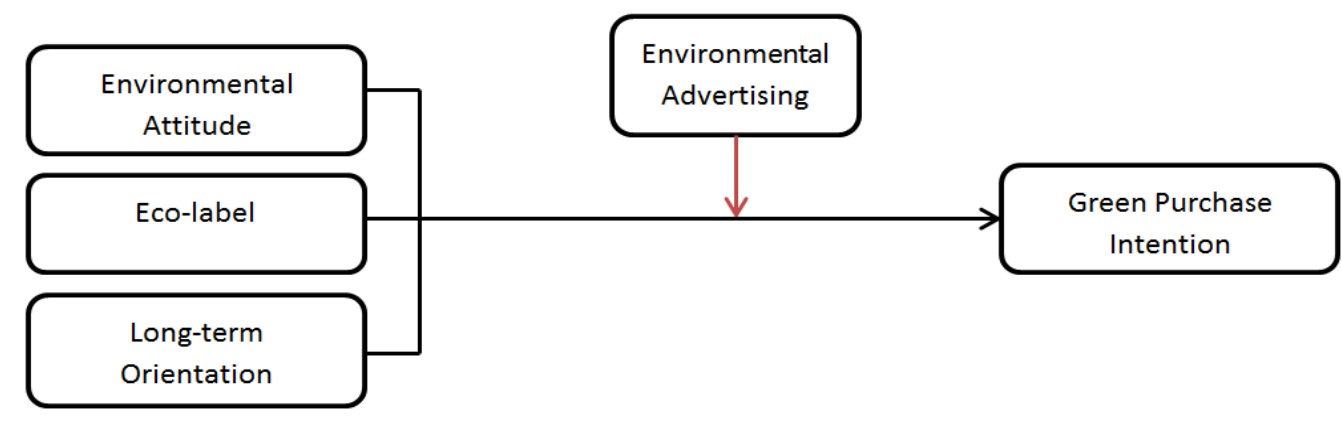

Figure 1. Research model

H1: There is a significant positive relationship between environmental attitude and green purchase intention.

$\mathrm{H} 2$ : There is a significant positive relationship between eco-label and green purchase intention.

H3: There is a significant positive relationship between long-term orientation and green purchase intention.

H4: Exposure to environmental advertising moderates the relationship between environmental attitude, eco-label, long-term orientation and green purchase intention.

\subsection{Sampling Procedures and Data Collection}

A total of 600 set of questionnaires were distributed to customers at the grocery shops and shopping malls and 337 were usable. The number of usable questionnaires is considered sufficient. Nunnaly, (1978) and Malhotra and Peterson, (2002) quoted that "to enhance generalization of our findings, a sample of 300 respondents is sufficient to test measurement scales in a research study". The questionnaires were distributed through convenience sampling because it is among the best mean of getting information efficiently and quickly (Sekaran, 2000). 


\subsection{Measures}

The questionnaire consisted of six sections. Section A of the questionnaire is on respondent's demographic profile such as gender, age, education household annual income and job sector.

Section B through section F of the questionnaire measured the dependent, independent and moderator variables which are green purchase intention, environmental attitude, eco-label, long-term orientation, and environmental advertising respectively which were adopted and adapted from various sources and were measured based on five (5) point Likert Scale as described in Table 1.

Table 1. Instruments sources and measures

\begin{tabular}{|c|c|c|}
\hline Instruments & Source(s) & Likert Scale \\
\hline Green Purchase Intention & Mostafa (2006) and Chan (2001). & $1=$ Very Unlikely, 5 = Very Likely \\
\hline Environmental Attitude & $\begin{array}{l}\text { Tanner and Kast (2003) and Chen and Chai } \\
\text { (2010). }\end{array}$ & $\begin{array}{l}1=\text { Strongly Disagree, } 5=\text { Strongly } \\
\text { Agree }\end{array}$ \\
\hline Eco-Label & Rahbar and Abdul Wahid (2011). & $\begin{array}{l}1=\text { Strongly Disagree, } 5=\text { Strongly } \\
\text { Agree }\end{array}$ \\
\hline Long-Term Orientation & Beard & $1=$ Very Unlikely, $5=$ Very Likely \\
\hline $\begin{array}{l}\text { Environmental } \\
\text { Advertising }\end{array}$ & Rahbar and Abdul Wahid (2011). & $\begin{array}{l}1=\text { Strongly Disagree, } 5=\text { Strongly } \\
\text { Agree }\end{array}$ \\
\hline
\end{tabular}

\section{Results and Discussion}

\subsection{Respondents Profile}

The profile of respondents include, age, gender, educational level, annual income and job sector.

Table 2. Profile of survey respondents

\begin{tabular}{lll}
\hline Demographics & Frequency (N=337) & Percentage (\%) \\
\hline Gender & 165 & 49 \\
Male & 172 & 51 \\
Female & & \\
Age (Years) & 4 & 1.2 \\
$18-19$ & 41 & 12.2 \\
$20-25$ & 106 & 31.5 \\
$26-30$ & 55 & 16.3 \\
$31-35$ & 34 & 10.1 \\
$36-40$ & 61 & 18.1 \\
$41-45$ & 21 & 6.2 \\
$46-50$ & 15 & 4.5 \\
51 and above & & \\
Education & 4 & 1.2 \\
Lower than secondary school & 18 & 5.3 \\
Secondary school or equivalent & 69 & 20.5 \\
Diploma or equivalent & 196 & 58.2 \\
Bachelor Degree & 37 & 11 \\
Master Degree & 13 & 3.9 \\
PhD & & \\
Household Annual Income & 14 & 4.2 \\
RM18000 and below & 78 & 23.1 \\
RM18001 - RM36000 & 98 & 29.1 \\
RM36001 - RM60000 & &
\end{tabular}




\begin{tabular}{lll}
\hline Demographics & Frequency $(\mathbf{N}=\mathbf{3 3 7})$ & Percentage (\%) \\
\hline RM60001 - RM96000 & 69 & 20.5 \\
RM96001-RM120000 & 42 & 12.5 \\
RM120001-RM180000 & 14 & 4.2 \\
RM180001 and more & 7 & 2.1 \\
Missing & 15 & 4.5 \\
Job & & \\
Government & 138 & 40.9 \\
Private & 169 & 50.1 \\
Self-employed & 6 & 1.8 \\
Unemployed & 24 & 7.1 \\
\hline
\end{tabular}

According to the data result in Table 2, gender has minimal next to less than two percent difference between both genders respectively male were 165 representing $49 \%$ of the participants and female were $172(51 \%)$. In addition, the majority of respondents aged between 26 to 30 years old (31.5\%), $18.1 \%$ aged between $41-45$ years old and $16.3 \%$ belongs to age group 31-35 years old with the mean of 34.42 years old. The distribution of the respondents in terms of education, about $73 \%$ of the respondents were studying or holding at least Bachelor degree. This shows that most of respondents are literate and promise a good result on the factors influencing green purchase intention. On the income level group breakdown, $68.4 \%$ of respondents have an annual household income of RM 36,001 or higher indicated majority of them belong to middle income groups as proposed by Economic Planning Unit of Malaysia while the mean for yearly income is RM68, 215.84. Furthermore $92.8 \%$ of the respondents have a job in private, government sector, or are self-employed.

\subsection{Factor Analysis}

A confirmatory factor analysis was conducted on all constructs of the current study which are green purchase intention, environmental attitude, eco-label, long-term orientation, and environmental advertising, 3 items of the total initial 36 items were omitted due to cross-loaded. The result of Kaiser-Meyer Oklin is .899 , and the Bartlett's Test of Sphericity is significant at $\mathrm{P}=.000$. Besides that, the eigenvalues of all the variables were above 1 while the factor loading values ranged from .584 to .980 . Hence, all the constructs were considered factorable and accepted for further analysis in line with the requirements by Coakes and Steed (2007) were Kaiser-Meyer-Oklin Measure of sampling adequacy (KMO) should be greater than 0.60 to assume factorable, while the initial Eigen value should be greater than 1 in order to be considered significance.

\subsection{Reliability Test}

According to Sekaran and Bougie (2010), reliability testing refers to the stability and consistency of instruments in a study. The reliability of all variables were examined for Cronbach's alpha score and presented in Table 3. Hair et al., (1998), recommended that Cronbach's alpha value should be above the threshold of 0.60 . Furthermore, Sekaran and Bougie (2010) specified that reliability is acceptable in the range of 0.7 and considered good when above 0.8. The yielded result of current study in Table 3 confirms that all constructs achieved Cronbach Alpha value of between 0.787 and 0.937 . Therefore, it is concluded that all the items enjoyed a good level of Cronbach's Alpha values.

Table 3. Reliability analysis

\begin{tabular}{lll}
\hline Variables & No. of Items & Cronbach's Alpha \\
\hline $\begin{array}{l}\text { Dependent Variable } \\
\text { - Green Purchase Intention }\end{array}$ & 5 & .937 \\
Independent Variables & & \\
- Environmental Attitude & 9 & .906 \\
- Eco-Label & 6 & .908 \\
- Long-Term Orientation & 6 & .882 \\
Moderating Variable & & .787 \\
- Environmental Advertising & 7 &. \\
\hline
\end{tabular}




\subsection{Descriptive Analyses}

In addition, results in Table 4 shows that green purchase intention have the highest mean score of 4.63 , followed by environmental attitude $(M=4.27)$, long-term orientation $(M=4.12)$, environmental advertising $(M=4.05)$ and eco-label $(\mathrm{M}=4.01)$. Hence, it can be confirmed that all of the mean scores reported were more towards "agree" to "strongly agree" or and "likely" to "very likely" opinions.

The standard deviation figures for all the variables under investigation as reported in Table 4 ranged from 0.527 to 0.768 ; indicates that the answers are normally distributed.

Table 4. Means and standard deviation

\begin{tabular}{lll}
\hline Variables & Mean & Standard Deviation \\
\hline Dependent Variable & & \\
• Green Purchase Intention & 4.63 & .76884 \\
Independent Variables & & \\
- Environmental Attitude & 4.27 & .52778 \\
- Eco-Label & 4.01 & .62830 \\
- Long-Term Orientation & 4.12 & .52760 \\
Moderating Variable & & \\
- Environmental Advertising & 4.05 & .56457 \\
\hline
\end{tabular}

\subsection{Hypotheses Testing}

In order to achieve the objectives of this study multiple regression analyses and hierarchical regression analysis were conducted. The coefficient of determination $R$ Square $\left(R^{2}\right)$ in Table 5 is .173 and significant at $(p<0.01)$. In other word, this indicated that 17.3 percent of green purchasing intention determinants were explained by environmental attitude, eco-label and long-term orientation. The F change was 23.275.

Table 5. Multiple regressions for hypothesis 1 through 3

\begin{tabular}{|c|c|c|c|c|c|}
\hline \multirow{2}{*}{ Model } & \multicolumn{2}{|c|}{ Unstandardized Coefficients } & \multicolumn{3}{|c|}{ Standardized Coefficients } \\
\hline & B & Std. Error & Beta & $\mathbf{t}$ & Sig \\
\hline (Constant) & 1.079 & .369 & & 2.923 & .000 \\
\hline Environmental Attitude & .277 & .117 & .190 & 2.362 & $.019^{*}$ \\
\hline Eco-label & .391 & .069 & .320 & 5.665 & $.000^{* *}$ \\
\hline Long-term orientation & .177 & .083 & .119 & 2.135 & $.033^{*}$ \\
\hline \multicolumn{6}{|l|}{$\mathrm{R}^{2}=.173$} \\
\hline \multicolumn{6}{|l|}{ Adjusted $\mathrm{R}^{2}=.166$} \\
\hline \multicolumn{6}{|l|}{ F Change $=23.275$} \\
\hline $\operatorname{Sig} F=.000$ & & & & & \\
\hline
\end{tabular}

Dependent Variable: Green Purchase Intention

Predictors: (Constant), Environmental Attitude, Eco-Label, Long-Term Orientation

** $\mathrm{P}$ value is significant at $<.01$

$* \mathrm{P}$ value is significant at $<.05$

\subsubsection{Relationship between Environmental Attitude and Green Purchase Intention}

The result of the analysis shows environmental attitude have a significant and positive relationship with green purchase intention $(\beta=0.190, p<0.05)$. This finding underpinned earlier studies by Abdul Wahid's et al., (2011) and Lee (2008). Moreover, studies conducted in Malaysia by Aman and Harun (2012), Chen and Chai (2010), Nik Abdul Rashid (2009), and Mun (2009), have suggested that consumers are more likely to engage in eco-friendly behavior if they possess a high level of environmental attitude. Also, attitude has been found to play 
a vital role mainly because it is believed to strongly influence consumers' behavior on the given issue of environment deterioration. Finding of this research indicates that environmental positive attitude is related with consumers' consumption behavior. This suggests that individuals who are genuinely concerned about environmental problems are more likely to take measures to prevent further environmental deterioration by having a positive purchase intention towards green products. Generally this is an automatic response generated by consumers where they feel morally obligated to conserve the environment. Hence, the finding of current study implies the fairly positive support to attitudes as one of the most important determinant of purchase intention regardless of sample size, time, geographic area or culture.

\subsubsection{Relationship between Eco-label and Green Purchase Intention}

Based on the regression analysis in Table 5, it is confirmed that eco-label enjoyed a significant and positive relationship towards green purchase intention $(\beta=.320, \mathrm{p}=.00)$. This finding is consistent with Abdul Wahid et al., (2011), D'Souza et al. (2006) and Thogersen (2000)'s study in which they found that consumers are getting environmental information from labels before deciding to purchase a green product. It is proven in this study that awareness and trustfulness of eco-label exert a significant influence in green purchase intention. Another important finding in this study is that eco label ranked as the top factor influencing on green products purchase intention. This favors the earlier statement in the literature, where eco-label is known as a vital marketing tool to assist consumers in identifying green products in the marketplace. In general, product's eco-labels offer an informative base to individuals in order for them to make a conscious choice over the conventional ones.

The finding of this study also affirm that eco-label is necessary and valuable for consumer in helping them in the purchase decisions process in which intention is found throughout the process. In addition, respondents in this study expressed their positive familiarity, perception and placed their trust in eco-labeled product. This is due to the improved application process and criterions by the government in order to award eco-label certification to producers like the SIRIM eco-label logo to vanish all the doubt in consumers mind.

\subsubsection{Relationship between Long-term Orientation and Green Purchase Intention}

The result in Table 5 accepted hypothesis 3 conceptualizing long-term orientation has a significant and positive influence on green purchase intention $(\beta=.119, \mathrm{p}<0.05)$. It is in line with Beardon et al., (2006) assertion that long-term orientation is a prominent facet of national culture and of itself influences consumers' purchase decision making process which intention is one of the steps. This finding also underpinned previous study by Samarasinghe (2012) which concluded that a long-term orientated individuality will ensure strong belief that could guide them to make wise decision by stimulating their overall trust on the product or action intended. Then in line with the long-term orientations' facets such as thrift and persistence to ensure future rewards, the respondents in this study shown a positive long-term orientation towards green purchase intentions as this consumption pattern saves money in the long and rewarding by conserving the environment to guarantee a better living for all. As such, the respondents in this study who have long-term orientation values will assess environmental friendly behavior/action such as engaging in green purchase intention is appropriate and reasonable to harmonize with environment.

To relate to the study in hand, based on the literature we can consider Malaysians to possess LTO values. This is due to the geographical area of Malaysia located in Asia, referred as having eastern policies and also having adequate proportion of Chinese people living in the country and blended with other races and ethnics from all walks of life. Indirectly, other races in Malaysia have been influenced or have started to instill Chinese philosophy of life when they are exposed to it in certain manners to achieve a successful life too. For example they forgo todays' part of leisure and invest more in property to ensure a stable and better future both for themselves and their children (i. e. education and future plan like business). Hence, Malaysians generally start to integrate cultural values of long-term orientation in their daily contact and decision making including favorable purchase intention and environmental friendly behavior.

\subsubsection{The Moderating Role of Environmental Advertising}

As established in the hierarchical regression of moderator analysis suggested by Aiken and West (1991) in Table 6, environmental advertising enjoys a significant moderating effect between environmental attitudes and long-term orientation on green purchase intention. Thereby, the coefficient result confirmed that exposure to environmental advertising is able to influence and strengthen the relationship between both consumers' environmental attitude towards green purchase intention and consumers' long -term orientation on green purchase intention. In other words, exposure to green advertising be incentivized to individuals who possess favorable environmental attitude and have cultural values by encouraging them to form stronger intention to buy green products. The current finding validated assumptions of previous studies by Rahbar and Abdul Wahid (2011) 
and Litvine and Wüstenhagen (2011) who suggested that green purchase decisions to some extent are determined by environmental advertising influence. Both studies highlighted that environmental advertising massage serves as a platform of information source that enhance consumer knowledge relate to green products and recognize the advantage of purchasing such product.

Table 6. Hierarchal regression for moderator of environmental advertising

\begin{tabular}{lllllll}
\hline Model & $\mathbf{R}$ & $\mathbf{R}^{2}$ & Adjusted $\mathbf{R}^{2}$ & $\mathbf{R}^{2}$ change & F change & Sig F Change \\
\hline 1 & $.416^{\mathrm{a}}$ & .173 & .166 & .173 & 23.275 & .000 \\
2 & $.419^{\mathrm{b}}$ & .176 & .166 & .002 & .949 & .331 \\
3 & $.455^{\mathrm{c}}$ & .207 & .190 & .031 & 4.342 & .005 \\
\hline
\end{tabular}

Dependent variable: Green Purchase Intention

a. Predictors: (Constant), EA, EL, LTO

b. Predictors: (Constant), EA, EL, LTO, A

c. Predictors: (Constant), EA, EL, LTO, A, AxEA, AxEL, AxLTO

Significance level at $\mathrm{p}<.05$

Likewise, results of the current study found that environmental advertising would enhances consumer's knowledge about green products, guide them to make an informed purchasing decision as well perceived it to be trustworthy and credible medium for channeling information about the green products and promoting consumer green purchase intention. This is possible that the consumer needs more information of the "how" to do it rather than the "what" it is all about that they get in formal or informal education and lifestyle. A noteworthy finding claimed by the sample of this study that green advertising alone leads them to be more socially responsible when it comes to environment related consumptions. It is explainable that if "green advertising appeals" match consumers' thoughts and thinking process, consumers will be more active in product as well as in purchase intention.

In addition, this study revealed another significant difference in role between green and normal products advertising is that the former is associated with environmental sustainability that help consumer to distinguish or identify the green product in market and its availability in the country. This would solve the challenges and confusing phase for consumers in distinguishing between the conventional products and actual green products.

\section{Implications}

This study contributes to the body of knowledge by investigating and validating the relationships of environmental attitude, eco-label, and long-term orientation as well a moderating influence of environmental advertising on green purchase intention in Malaysia, certainly a non-western setting, by using the Theory of Planned Behavior (TPB) to explain the conceptual framework. From the obtained results, overall variables relationships were found to enrich the explanation of the Theory of Planned Behavior in predicting consumers' green purchase intention. Developing such model is important for filling in the gap of information which exists between marketers (as evidenced by widespread use of green products) and academician (as evidenced by insufficient of research on green purchasing behavior). Therefore, marketers can make use of these findings to refine their marketing plans particularly for green products.

The most important implication to those industries involved in green related products is that eco-label can serve as an essential marketing tool in promoting green consumption among consumers. Marketers should focus on providing clear information about green products via eco-labels in order to promote consumer familiarization and enhance their knowledge relate to green products. It is strongly suggested that green product manufacturers should immediately obtain the eco-label on product packaging to increase the prevalence of eco-labeled products in the marketplace since the consumer's ability to recognize and understand them is proved undoubtedly the latter influences their green product purchase intention.

As established in this study that environmental attitude found to be important in influencing green purchase intention. Hence it is suggested for the green marketers to promote their green products based on cause-related marketing method rather than viral marketing method. Coddington (1990) quoted that "the seeds that are sown under the right approach to environmental marketing are the seeds of environmental education". Thus by having adequate environmental knowledge and decent understanding on how they can help improve or stop the 
environment deteriorations, consumers will form a positive attitude towards environment the latter be more encouraged to purchase green product.

Lastly, the researcher can conclude that marketers need to redesign or refine their current environmental advertisements concept by instilling some long-term orientation values. By doing this, it will be able to promote on how this green products can help the environment, save money and also time in which benefits in a long run as well as to remind individuals of their responsibility to do so since human is part of nature to preserve it and not otherwise. This will confront consumer to perceive the idea and concept of green products differently than current environmental massages that promote green products no different than conventional products by only highlighting its' regular benefits, improved functions and recycled material. Also, a green advertisement should be associated with an informative yet concise and transparent claim to grab the consumers' attention and instantaneously be able to lay consumers' doubts and gain credibility with the public to a certain extent since it is perceived as a platform by consumers to increase their knowledge about green products and be more environmentally concern.

\section{Limitations}

This study identified and investigated few factors inducing purchase intentions of green products, yet there are other factors found in the literature of previous studies to motivate consumers' purchasing intention in other field of product categories. For instance, environmental concern, psychological factor, demographic factors and product related attributes.

Another limitation of current study is the survey method i.e. filling of the questionnaire. This method sometimes unable to provide the accurate response since some respondents simply fill up the questionnaire without knowing the importance of the question asked. For that reason, interview method might solve this problem if not completely may be partly.

\section{Suggestions for Future Research}

This study has investigated the determinant of green purchase intention of green products in general. Thus, future research can be focused on a specific product. It is possible by concentrating specifically on home electric and electronic appliances, hybrid cars or on the industry such as food or agriculture.

\section{References}

Aiken, L. S., \& West, S. G. (1991). Multiple regression: Testing and interpreting interactions. Newbury Park: Sage.

Ajzen, I. (1985). In J. Kuhl, \& J. Beckmann (Eds.), From intentions to actions: A theory of planned behavior, in action control: From cognition to behavior (pp. 11-39). New York: Springer Verlag.

Ajzen, I. (1991). The theory of planned behavior. Organizational at Behavior and Human Decision Processes, 50, 179-211. http://dx.doi.org/10.1016/0749-5978(91)90020-T

Ali, A., Khan, A. A., \& Ahmed, I. (2011). Determinants of Pakistani consumers' green purchasing behaviour: Some insight from a developing country. International Journal of Business and Social Science, 2(3), 217-226.

Aman, L. A. H., Harun, A., \& Hussein., Z. (2012). The Influence of Environmental Knowledge and Concern on Green Purchase Intention the Role of Attitude as a Mediating Variable. British Journal of Arts \& Social Sciences, 7(2), 145.

Armstrong, J. S., Morwitz, V. G., \& Kumar, V. (2000). Sales forecasts for existing consumer products and services: Does purchase intention contribute to accuracy? International Journal of Forecasting, 16(3), 383-397. http://dx.doi.org/10.1016/S0169-2070(00)00058-3

Aspinall, D. (1993). Home economics and technology. Chicago: Small Waters.

Bator, R., \& Cialdini, R. (2000). New ways to promote pro-environmental behavior: The application of persuasion theory to the development of effective pro-environmental public service announcements. Journal of Science, 56(3), 527-541.

Bergeron, J. (2004). Enhancing Customers Purchase intention and Positive Word-of-mouth in the Banking Industry. Competitive Paper ACR Proceeding, 1-20.

Chan, R. Y. K. (2001). Determinants of Chinese Consumers' Green Purchasing Behaviour. Psychology and Marketing, 18(4), 389-413. http://dx.doi.org/10.1002/mar.1013 
Chase, D., \& Smith, T. K. (1992). Consumers keen on green but marketers don't deliver. Advertising Age, 63.

Chen, T. B., \& Chai, L. T. (2010). Attitudes towards the environment and green products: Consumers' perspective. Management Science and Engineering, 4(2), 27-39.

Coakes, S. J., \& Steed, L. (2007). SPSS Version 14.0 for windows: Analysis without anguish. Milton, Australia: John Wiley \& Sons.

Coddington, W. (1990). It's no fad: Environmentalism is now a fact of corporate life. Marketing News, American Marketing Association, 24(21), 7.

D'Souza, C., Taghian, M., \& Lamb, P. (2006). An empirical study on the influence of environmental labels on consumers. Corporate Communication: An International Journal, 11(2), 162-173. http://dx.doi.org/10.1 108/13563280610661697

Fishbein, M., \& Ajzen, I. (1975). Belief, Attitude, Intention, and Behavior: An Introduction to Theory and Research. Reading, MA: Addison-Wesley.

Giridhar, T. R. (1998). Eco-labeling: A comparative analysis. Chemical Business, 12(7), 95-99.

Hackett, P. M. W. (1993). Consumer's environmental concern values: Understanding the structure of contemporary green world views. European Advances in Consumer Research, 1, 416-427.

Hofstede, G. (2001). Culture's consequences: Comparing values, behaviors, institutions, and organizations across nations (2nd ed.). Thousand Oaks, California: Sage Publications, Inc.

Hopper, J. R., \& Nielsen, J. M. (1991). Recycling as altruistic behaviour: Normative and behavioural strategies to expand participation in a community recycling program. Environment and Behaviour, 23(2), 195-220. http://dx.doi.org/10.1177/0013916591232004

Laroche, M., Bergeron, J., \& Barbaro-Forleo, G. (2001). Targeting consumer who are willing to pay more for environmentally friendly products. Journal of Consumer Marketing, 18(6), 503-520. http://dx.doi.org/10. 1108/EUM0000000006155

Lee, K. (2008). Opportunities for Green Marketing: Young Consumers. Marketing Intelligence and Planning, 26(6), 573-586. http://dx.doi.org/10.1108/02634500810902839

Litvine, D., \& Wüstenhagen, R. (2011). Helping "light green" consumers walk the talk: Results of a behavioural intervention survey in the Swiss electricity market. Ecological Economics, 70, 462-474. http://dx.doi.org/10. 1016/j.ecolecon.2010.10.005

Malhotra, N. K., \& Peterson, M. (2006). Basic Marketing Research: A Decision-Making Approach. Upper Saddle River, New Jersey: Pearson Prentice Hall.

Massachusetts Department of Environmental Protection. (2002). Barrier/Motivation Inventory No. 3. Retrieved August, 2014, from http://www.state.ma.us

McCarty, J. A., \& Shrum, L. J. (2001). The Influence of Individualism, Collectivism, and Locus of Control on Environmental Beliefs and Behavior. Journal of Public Policy \& Marketing, 20, 93-104. http://dx.doi.org /10.1509/jppm.20.1.93.17291

Mostafa, M. M. (2006). Antecedents of Egyptian consumers' green purchase intentions: A hierarchical multivariate regression model. Journal of International Consumer Marketing, 19(2), 97-126. http://dx.doi.org/10.1300/J046v19n02_06

Mun, C. C. (2009). A Study on Consumers' Green Purchasing Intention. Unpublished Thesis Master of Business Administration. Universiti Utara Malaysia.

Newberry, C. R., Klemz, B. R., \& Boshoff, C. (2003). Managerial implications of predicting purchase behavior from purchase intention: A retail patronage case study. Journal of Services Marketing, 17(6), 609-620. http://dx.doi.org/10.1108/08876040310495636

Nunally, J. C. (1978). Psychometric Theory (2nd ed.). New York: McGraw Hill.

Peter, J. P., \& Olson, J. C. (2008). Consumer behaviour and marketing strategy (8th ed.). New York, NY: McGraw-Hill Education.

Rahbar, E., \& Wahid, N. A. (2011). Investigation of green marketing tools' effect on consumers' purchase behavior. Business Strategy Series, 12(2), 73-83. http://dx.doi.org/10.1108/17515631111114877

Rashid, N. R. N. A. (2009). Awareness of eco-label in Malaysia green marketing initiative. International Journal 
of Business and Management, 4(8), 132-141. http://dx.doi.org/10.5539/ijbm.v4n8p132

Samarasinghe, R. (2012). The Influence of Cultural Values and Environmental Attitudes on Green Consumer Behaviour. International Journal of Behavioral Science, 7(1), 83-98.

Schultz, P. W., \& Zeleny, L. C. (2000). Promoting environmentalism. The Journal of Social Issues, 56(3), 443-457.

Sekaran, U., \& Bougie, R. (2010). Research Methods for Business: A Skill Building Approach. UK: John Wiley $\&$ Sons.

Sian, L. F., Chuan, S. C., Kai, B. S., \& Chen, B. O. (2010). Culture and consumer behaviour: Comparison between Malays and Chinese in Malaysia. International Journal of Innovation, Management and Technology, 1(2).

Stern, P. C., \& Dietz, T. (1994). The value basis of environmental concern. Journal of Social Issues, 50(3), 65-84. http://dx.doi.org/10.1111/j.1540-4560.1994.tb02420.x

Thogersen, J. (2000). Psychological determinants of paying attention to eco-labels in purchase decisions: Model development and multinational validation. Journal of Consumer Policy, 23, 285-313. http://dx.doi.org /10.1023/A:1007122319675

Tsen, C. H., Phang, G., Hasan, H., \& Buncha, M. R. (2006). Going green: A study of consumers' willingness to pay for green products in Kota Kinabalu. Int. J. Bus. Soc., 7, 40-54.

Vining, J., \& Ebreo, A. (1992). Predicting recycling behaviour from global and specific environmental attitudes and changes in recycling opportunities. Journal of Applied Social Psychology, 22(20), 1580-1607. http://dx.doi.org/10.1111/j.1559-1816.1992.tb01758.x

Wong, V., Turner, W., \& Stoneman, P. (1996). Marketing strategies and market prospects for environmentally friendly consumer products. British Journal of Management, 7(3), 263-281. http://dx.doi.org/10.1111/j. 1467-8551.1996.tb00119.x

\section{Copyrights}

Copyright for this article is retained by the author(s), with first publication rights granted to the journal.

This is an open-access article distributed under the terms and conditions of the Creative Commons Attribution license (http://creativecommons.org/licenses/by/3.0/). 